\title{
EL SENTIMIENTO DE LA POSGUERRA: LA REVISTA DE SANTANDER Y EL EXISTENCIALISMO, 1945-1967
}

\author{
The Sentiment of the Post-War: Revista de \\ SANTANDER AND EXISTENTIALISM, 1945-1967
}

Angie Daniela Ortega Rey ${ }^{1}$, Juliana Villabona Ardila ${ }^{2}$,
Álvaro Acevedo Tarazona
${ }^{3}$

Artículo derivado de la investigación:
"Prensa y política en Santander: ideología,
violencia y accionar partidista, 1930-1946",
Código 2334 financiado por la Vicerrectoría
de Investigación y Extensión de la
Universidad Industrial de Santander.

Cómo citar este artículo: Acevedo Tarazona, Á., Ortega Rey, A. D. y Villabona Ardila, J. (2019). El sentimiento de la posguerra: la Revista de Santander y el existencialismo, 1945-1967. Estudios de Literatura Colombiana 45, pp. 49-66. DOI: https://doi.org/10.17533/ udea.elc.n $45 \mathrm{a} 03$

angied.ortega@hotmail.com

Universidad Industrial de Santander, Colombia

2 villabonardila@hotmail.com

Universidad Industrial de Santander, Colombia

3 tarazona20@gmail.com

Universidad Industrial de Santander, Colombia

Recibido: 26.01 .2019

Aprobado: 24.04.2019

Copyright: $\odot 2019$ Estudios de Literatura Colombiana. Este es un artículo de acceso abierto distribuido bajo los términos de la Licencia Creative Commons Atribución No comercial - Compartir igual 4.0 Internacional

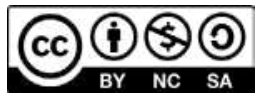

Resumen: la Revista de Santander se constituyó en un referente intelectual del departamento de Santander desde su primera entrega en junio de 1945, pues abrió una puerta para que el pensamiento crítico fuera expresado por las letras de intelectuales tanto nacionales como extranjeros, mostrando en sus páginas las grandes ideas y preocupaciones que embargaron al espíritu de la época en sus diversas formas de manifestación. El propósito de este artículo es presentar la Revista de Santander desde la perspectiva del contenido, centrando la mirada en la corriente filosófica del existencialismo, identificada como una influencia relevante dentro de la atmósfera literaria de la época.

Palabras clave: existencialismo; filosofía; literatura; Revista de Santander; violencia.

Abstract: Revista de Santander became an intellectual reference of the department of Santander since its first delivery in June 1945, because it opened a door for critical thinking to be expressed by the letters of both national and foreign intellectuals, showing on its pages the great ideas and concerns that seized the spirit of the time in its various forms of manifestation. The purpose of this article is to present the Revista de Santander from the perspective of the content, focusing on the philosophical current of existentialism, identified as a relevant influence within the literary atmosphere of the time.

Keywords: Existentialism; Philosophy; Literature; Revista de Santander; Violence. 


\section{Presentación}

La Revista de Santander, publicada entre los años de 1945 y 1967, logró consolidarse, pese a su falta de periodicidad, como un referente en materia cultural e intelectual del departamento de Santander (Colombia). La calidad de sus primeras publicaciones, aunada al nutrido grupo de escritores que con su espíritu crítico dieron vida a las páginas de cada una de las dieciocho entregas conocidas de la revista, la llevaron a convertirse en una tradición cultural altamente apreciada por distintas esferas de la sociedad santandereana. Por ello, para el año 2006 y ante la carencia de una revista de amplia difusión en materia cultural hecha en el departamento, la Universidad Industrial de Santander abrió la puerta a la segunda época de la Revista de Santander, una apuesta por mantener vigente esa tradición intelectual nacida en la década de 1940, desde una perspectiva moderna (Beltrán, 2006, pp. 7-9).

El presente artículo se propone presentar esta revista desde la perspectiva del contenido, centrando la mirada en la corriente filosófica del existencialismo, identificada como una influencia relevante en la atmósfera literaria de la época. Así pues, el texto se divide en tres momentos: en el primero se realiza una breve descripción del ambiente político y cultural que acompañó la aparición de la Revista de Santander; en el segundo, se presenta la revista con todos los rasgos característicos que la hicieron convertirse en un referente en materia cultural del departamento; por último, se introduce el existencialismo como una tendencia que impregna las variadas temáticas de la revista, desde la cual cada autor, con una perspectiva diferente de las letras, asimiló e incorporó a su discurso de tal manera que es posible hallar ciertos rasgos propios de esta corriente en los textos seleccionados.

\section{Ambiente político y cultural}

El panorama cultural del departamento de Santander se vio sacudido desde la década de 1920 por la aparición de pequeñas revistas literarias y de variedades, hoy fuera de circulación, que iniciaron en las letras a los más destacados intelectuales, académicos, periodistas y políticos de la región oriental de Colombia. El frenesí por las publicaciones periódicas en sus diferentes formatos no hizo sino aumentar en las décadas siguientes. La aparición de las publicaciones de variedades (magazines de deportes, cocina, revistas sociales, etc.) de las primeras décadas del siglo xx aún no han sido bien estudiadas. Un fenómeno similar se viviría con las revistas literarias. En la Biblioteca Nacional de Colombia hay registrado un variado número 
de publicaciones periódicas editadas en Santander desde 1920: Bombos y Palos (1932), La Escena: Propaganda, Información, Literatura, Deportes y Variedades (1932), Oriente: Revista Literaria (1933), Órbita: Revista Literaria (1934), Rumbos (1939-1941), Revista Stadium: Revista Deportiva, Literaria (1940-1977), Aurora: Revista Mensual (1938-1942) y Cordillera: Revista de Santander para Colombia (1948-1953), entre otras.

Todas estas revistas conectaron a una pequeña ciudad como Bucaramanga con un mundo que poco a poco empezó a ser conocido, leído y reinterpretado. Las revistas literarias, por su parte, fueron el vehículo que permitió que una nueva generación de políticos e intelectuales entraran a la arena pública. Las sedes de los diarios y revistas fueron en la ciudad de Bucaramanga lugares de sociabilidad interpartidista, donde se discutía sobre política y literatura. Un ambiente de cordial intercambio entre sectores influyentes de la ciudad es el que describe Manuel Serrano Blanco en su autobiografía titulada La vida es así (1989), cuando señala que el club, las librerías, los cafés, las sociedades y academias fueron otros de los lugares donde se compartían, se discutían y se moderaban las tensiones políticas (p. 556).

En Bucaramanga, la revista Motivos, fundada por Jaime Barrera Parra y Luis Ardila Gómez, reunió alrededor de la actividad intelectual a jóvenes como José Camacho Carreño, Gabriel Turbay, Carlos Valencia Estrada, Alejandro Galvis Galvis, Juan Cristóbal Martínez, Camilo Barrera Vargas y Manuel Serrano Blanco, una generación ansiosa por encontrar su lugar en el mundo. Aun siendo los más fieros representantes de sus respectivos partidos, no temieron enfrentarse a la tradición. La paz, que ya por varias décadas se había mantenido en el país desde la Guerra de los Mil Días, se vio perturbada por estas generaciones que, con nuevas influencias filosóficas, sentían la imperiosa necesidad de transformar las instituciones políticas, económicas y sociales del país, pero también a su población a la que consideraban "mestizos pertenecientes a un subgrupo étnico inferior" (Henderson, 2006, p. 218). El mayor obstáculo lo constituyó la vieja política anclada en el siglo xIX y poco dada a los cambios; por ello, el escenario de combate iniciaría en las letras.

El afán por publicar, por traer nuevas ideas y por modernizar al país se ve reflejado en el gran número de publicaciones periódicas que seguirían apareciendo y desapareciendo a través de los años. No era fácil llevar a cabo esta labor; las pobres condiciones económicas marcaron el devenir de muchas revistas culturales y literarias. La queja constante era, 
por tanto, el atraso en la información, de la población y de los pocos libros. Estos sin duda eran esfuerzos por traer ese gran mundo, por sortear las difíciles condiciones geográficas, por no quedarse atrás de un progreso esquivo que andaba sobre rieles y que en muy poco tiempo surcaría los aires. Desde esta perspectiva, el progreso económico y cultural obsesionó tanto a liberales como a conservadores desde siempre. Con esta idea fueron educados mandatarios, políticos, escritores y periodistas en toda América Latina desde finales del siglo XIX y principios del XX.

Un ejemplo de este deseo modernizador puede hallarse en Los Nuevos, una generación nacida a inicios del siglo xx, que en la década de 1920 se enfrentó a sus mayores, inclusive de sus propios partidos, quienes tendrían entre 30 y 40 años en aquella época, e irrumpieron con un mismo afán literario en el escenario nacional. El propósito era renovar la política y la literatura. Los jóvenes se reunían en cafés y sociedades literarias para discutir sobre poesía y la vida política del país. Antes de saltar a la arena pública, estos jóvenes se iniciaron en la literatura como cronistas, columnistas, poetas, críticos literarios y traductores. Sería una labor que no olvidarían por el resto de sus días. Las publicaciones impresas les permitieron ingresar en la vida política a temprana edad.

No era de extrañar quelos enfrentamientos, las tensiones ylas disputas estuvieran servidos. A diferencia de la generación de 1870, cansada de las guerras civiles, para los nuevos grupos la concordia y la moderación fueron sinónimos de cobardía. Se rescataron la altivez, la fuerza y la beligerancia como valores supremos de la política. Estas nuevas generaciones vivieron en un contexto de polarización y violencia causadas en parte por su propia retórica. Para la década de 1940, el ambiente de sana convivencia había desaparecido. El país se sumergía en un proceso de autodestrucción, guerra civil y suspensión del gobierno democrático (Henderson, 2006, p. 421).

Inmersas en tal entorno, dichas generaciones llegarían a la cima de su popularidad política e intelectual en la década de 1950. No obstante, el contexto al que se enfrentaban cambiaba rápidamente. Así como en la década de 1920, ellos habían atacado a sus predecesores, ahora se convertían en blanco de críticas por sus propias actuaciones y por la violencia. Si alguna vez habían sido la vanguardia y las nuevas voces, hacia la década de 1950 y 1960 pasaron a ser considerados la retaguardia. De este modo, irrumpe en Colombia una actividad cultural importante con una serie de publicaciones en la que harían carrera los escritores más destacados del 
momento (Acevedo, 2017, p. 556). El panorama cultural se transformaba nuevamente. En 1955 fue fundada la revista Mito por Jorge Gaitán Durán y Hernando Valencia Goelkel. Le seguirían la revista Eco, editada en 1960, Nadaísmo 70, a principios de la década siguiente, y ya a finales de la década de 1970 aparece Alternativa. Todas estas revistas contaban entre sus directores y colaboradores a las principales figuras de las letras colombianas de aquellos años: Jorge Gaitán Durán, León de Greiff, Gabriel García Márquez, Álvaro Mutis, Gonzalo Arango, Jaime Jaramillo Escobar, entre otros. Por las páginas de estas revistas y otras menos conocidas se extendería una nueva revolución cultural.

En este ambiente aparece la Revista de Santander, cuyo primer número fue publicado en 1945, año en el que la política en Santander estaba caldeada por los constantes enfrentamientos entre líderes de los respectivos partidos y los brotes de violencia en diferentes municipios del departamento. Dicho enfrentamiento quedó ejemplificado en los ataques entre El Deber, diario conservador de propiedad de Manuel Serrano Blanco y Juan Cristóbal Martínez, y Vanguardia Liberal, de Alejandro Galvis Galvis. En dos ocasiones, 1932 y 1946, las instalaciones del primer diario serían destruidas, en parte como consecuencia de la labor incendiaria de los diarios. Poco a poco la prensa presentó a sus lectores un discurso claro y contundente: el partido contrario era el asesino de los copartidarios. Los conservadores culparon constantemente a Galvis Galvis de ser el causante de la violencia que se había desarrollado tempranamente en el departamento de Santander en 1930, cuando fue designado gobernador del departamento. Por su parte, los liberales culparon a los conservadores de la violencia en 1946. Ambos grupos se valieron de todo un arsenal retórico, de columnas, de caricaturas y, sobre todo, de las noticias, titulares y editoriales para repetir el mismo mensaje, aun sabiendo que este caería en un terreno caldeado. $\mathrm{Y}$, sin embargo, en este mismo contexto, se funda una revista con la participación de destacados miembros de ambos partidos en la que poco o nada se habla de política.

\section{La revista}

Durante el mes de junio de 1945 salió a la luz la primera entrega de la Revista de Santander, cuyos dos mil ejemplares fueron editados por la Secretaría de Instrucción Pública del Departamento, convirtiéndose rápidamente en un referente intelectual en el que destacados escritores 
expresaron sus inquietudes conforme al espíritu cosmopolita que los animaba. Contó con dieciocho números, los cuales circularon de forma periódica hasta 1950, momento en que culmina el primer ciclo de entregas de la revista. Para 1957 se reanudan las publicaciones hasta 1960. Tras una nueva suspensión, en 1963 la Secretaría de Extensión Cultural de Santander dirige los dos siguientes números, para posteriormente realizar una pausa de casi tres años que finalizó con la aparición del último ejemplar conocido de la revista, en 1967.

La calidad de sus primeras publicaciones se dio gracias al nutrido grupo de escritores que colaboraron con sus textos en la revista. El artículo inaugural fue escrito por Alejandro Galvis Galvis - gobernador del departamento en ese momento-, y se tituló "Función social de nuestra Universidad". El artículo mostraba la preocupación, tanto del autor como del círculo social y político al que pertenecía, por impulsar el desarrollo económico y cultural de la ciudad de Bucaramanga, dejando a un lado las diferencias políticas, a propósito de la creación de la Universidad Industrial de Santander. Esta y las siguientes dos entregas de la revista estuvieron bajo la dirección de Gustavo Serrano Gómez, junto con Abdón Espinosa Valderrama, Jaime Ardila Casamitjana y Manuel Serrano Blanco en el cuerpo de redacción.

En 1946 Jaime Ardila Casamitjana, escritor santandereano, quien estaba en la cima de su carrera gracias a la publicación en Buenos Aires de su novela Babel (1944), asumió la dirección de la revista para las entregas de enero y junio de 1946. Ese mismo año, Alberto Duarte French lo sucedió como director de los números de noviembre de 1946 y marzo de 1947. Para el año siguiente, Jorge Sánchez Camacho asumió la tarea de director de las dos siguientes entregas. Ya en 1950, Henry Serrano Uribe se hizo cargo del número diez de la revista, dando cierre así a un primer ciclo de publicaciones al que sucederían siete años de silencio editorial.

Fue en 1957 cuando Roberto Harker Valdivieso reanudó el tiraje de la revista hasta mayo de 1959, presentando los números de diciembre de 1957, julio y octubre de 1958 y mayo de 1959, fecha en la que dejaría de circular nuevamente. Reaparecería poco tiempo después, en 1960, siendo Rafael Prada Ardila el encargado de dar vida a la decimoquinta entrega en abril de ese año. Después de una nueva suspensión de casi tres años, Isabel Sorzano de Ibarnegaray publicó las entregas dieciséis, en enero de 1963, y diecisiete, en julio de 1964, para en seguida realizar otra larga pausa que culminaría en 
marzo de 1967 con la aparición del último número conocido de la Revista de Santander, a cargo de la poetisa Carmen Ortiz de Gómez Mejía.

En la revista se distinguieron tres secciones claramente demarcadas y precedidas por un sumario. La primera de ellas se denominó "Hombres e Ideas", un espacio dedicado esencialmente a la presentación de los autores que el lector tendría la oportunidad de disfrutar en las siguientes páginas. En la segunda sección se incluyó toda la producción escritural de los colaboradores; para ello, los textos se presentaron de modo tal que un ensayo de gran extensión se encontrase precedido por una poesía, un cuento, un capítulo de novela o una traducción de características más ligeras. La tercera y última sección denominada "Notas" permitió generar un breve espacio de opinión, en el que tanto los encargados de la revista como otras personalidades del ambiente cultural, político e intelectual pudieron manifestar abiertamente sus diversas perspectivas acerca de temas como la actualidad del país y de la ciudad, el arte, la literatura, eventos importantes y las obras de otros escritores; incluso, se dedicaron algunas páginas a lectores que quisiesen expresar su forma de ver la revista realizando críticas y aportes al trabajo del grupo de redacción; asimismo, se publicaron pequeñas referencias en que tanto periódicos nacionales como locales exaltaban la labor de la Revista de Santander.

\section{El existencialismo}

Si bien las siguientes líneas se concentran en el existencialismo como una influencia creciente en los autores que publicaron en la Revista de Santander de la primera época, también buscan mostrar una interpretación del existencialismo como filosofía que impregna, como ninguna otra, la atmósfera espiritual del siglo xx; por ello, es necesario, en un primer momento, comprender cuáles son los aspectos que entraña esta posición ante el mundo, para de este modo ingresar específicamente a los artículos que la revista aquí estudiada ofreció al lector de mediados del siglo pasado.

Dicho esto, resulta importante precisar que el existencialismo será considerado de conformidad con la interpretación de Norberto Bobbio (1949), quien sugiere que la filosofía de la existencia no fue una simple moda que surgió y se divulgó en los cafés franceses durante los años de la posguerra, sino que esta perteneció a "una manera de filosofar que responde extraña y maravillosamente a la vocación filosófica, hasta diría al gusto filosófico de nuestro tiempo" (p. 13). Esto quiere decir que más allá de ser 
una doctrina, hija de la crisis de la posguerra, es una actitud espiritual que trasciende las teorizaciones de los filósofos que han intentado definirla, hasta llegar a ser calificada como la filosofía de "nuestro tiempo".

Sin embargo, lo anterior no quiere decir que su génesis haya tenido lugar específicamente en el seno del siglo xx; con esto se sugiere que la filosofía de la existencia es el resultado de varias épocas que terminaron por engendrar una crisis, no una de tipo material sino espiritual, que lleva al hombre a mirar al mundo con cierto desencanto y a hacerse consciente de su propia contingencia y desamparo. De este modo, se logra observar que el existencialismo nunca ha sido una escuela filosófica uniforme y sistematizada, como solían serlo las filosofías tradicionales del siglo XIX, debido a que se encuentra compuesta por un racimo de filosofías y literaturas que desde perspectivas muy diferentes, como el cristianismo, el agnosticismo o el ateísmo, conducen al hombre a la adquisición de una conciencia para tomar posición frente a la vida, ante sí mismo y ante la sociedad de su época, pues "el hombre no es persona en el círculo cerrado de su individualidad, sino que deviene persona en la sociedad de los otros hombres" (Bobbio, 1949, p. 73).

Entre los personajes más destacados de esta corriente se encuentran: Fiódor Dostoievski (1821-1881), Søren Kierkegaard (1813-1855), José Ortega y Gasset (1883-1955), Karl Jaspers (1883-1969), Martin Heidegger (1889-1976) y Gabriel Marcel (1889-1973). No obstante, aquí nos concentramos en el caso particular de Jean Paul Sartre (1905-1980) que, aunque no fue el primer exponente de esta corriente, sí destaca por haber popularizado el término "existencialismo" al adherir su postura filosófica a esta denominación. Sus postulados fueron ampliamente comentados por tratar temas polémicos como la condición humana, la libertad, la acción, la responsabilidad, el compromiso, la trascendencia, la angustia y la nada, entre otros, no solo como parte de un compendio de teorías filosóficas sino también como conceptos aplicables a diferentes realidades, entre ellas la literaria.

Se puede afirmar que a partir de esto el existencialismo comenzó a tomar fuerza en diversos ambientes, principalmente en el literario, pues Sartre ligó su literatura al sentido del compromiso al afirmar que escribir es ante todo comprometerse, con los demás, con uno mismo, con una elección o con una idea (Sartre, 1950). Entonces, la literatura es la mejor forma de desplegar este compromiso para que llegue tanto al hombre del 
común como al académico, debido a que por medio de las representaciones ficcionales se logra dar cuerpo a los postulados que la filosofía esboza de forma teórica.

En el caso sartreano, dichos axiomas se hallaron sintetizados en textos como "El existencialismo es un humanismo", donde el autor se defiende de los constante ataques que lo acusaban de promulgar una filosofía de la desesperación, de hacer énfasis solo en el lado oscuro de la naturaleza humana, de suprimir a Dios y negar los valores del hombre. Ante tales acusaciones, Sartre afirma que su filosofía, lejos de ser contemplativa, es una filosofía de la acción, y va más allá al agregar que, según esta idea, el hombre no es otra cosa que un producto de sus actos, pues es por medio de ellos que se va configurando su verdadera esencia. Así, el existencialismo que Sartre representa declara que Dios no existe y que solo hay un ser en el que la existencia precede a la esencia y ese es el hombre, quien es el único responsable de sus elecciones y por ende de su devenir (Sartre, 2009).

Visto así, el momento en el que emerge la filosofía de la existencia resulta clave en la conformación de una nueva visión de mundo, debido a que la atmósfera del "sin sentido" que cubrió aquellos años de la posguerra permitió que muchas personas, entre ellas músicos, escritores, poetas e intelectuales, se vieran atraídas por estas ideas, convirtiéndolas en experiencias propias de la modernidad. En el ámbito colombiano, la filosofía moderna estuvo dominada por el neotomismo, que se impuso como reacción al utilitarismo y al positivismo de la época. Durante toda la República Conservadora (1886-1930), esta apareció como la filosofía oficial (Jaramillo Vélez, 1998, p. 97).

Con esto, resulta claro que la posición imperante de la Iglesia sobre la educación pública no favoreció el desarrollo de un pensamiento filosófico sólido, que tuvo que madurar lentamente hasta encontrar lugar en el ambiente más secular que caracterizó a la República Liberal (1930-1946). Es curioso observar que por esta época fueron intelectuales vinculados por sus orígenes a la provincia colombiana los que contribuyeron a la modernización de la filosofía, la cual estuvo "bajo la influencia de Ortega, de Kelsen y Scheller, más tarde de Husserl, Heidegger, Jaspers y Sartre — para mencionar únicamente los nombres más sintomáticos_-" (Jaramillo Vélez, 1998, p. 95).

Una influencia más temprana proviene de la filosofía alemana, concretamente de Friedrich Nietzsche. Fueron Guillermo Valencia, Max Grillo, José Asunción Silva y Baldomero Sanín Cano los primeros en acercarse 
a los trabajos de este filosofo por medio de la formación de una tertulia a la que Valencia bautizaría como "La gruta de Zaratustra", donde se encargaron de difundir y estudiar las ideas del alemán. Este primer acercamiento daría lugar a una creciente tendencia que llevaría al estudio principalmente de filósofos alemanes, y que en la década de los cincuenta les permitiría a académicos como Rafael Carrillo Luque, Danilo Cruz Vélez y Rafael Gutiérrez Girardot asistir a los seminarios de Karl Jaspers y Martín Heidegger.

En este orden de ideas, puede notarse que quienes escribieron para la Revista de Santander no se quedaron atrás en cuanto a las vanguardias intelectuales que surgieron alrededor del mundo, ya que los personajes que conformaron este grupo de autores destacaron por haber sido grandes estudiosos, hombres letrados que debido a los diversos oficios que desempeñaron se sumergieron de lleno en la vida cultural e intelectual. Así, se puede decir que el ingreso del existencialismo a Colombia y en específico a Santander tuvo mucho que ver con el hecho de que estos escritores no fueron ajenos a la situación que experimentaba Occidente en aquella época, dejando ver en sus escritos, unos de forma totalmente abierta y otros con alusiones más tímidas, las preocupaciones comunes de un mismo espíritu o, si se permite, de la atmósfera espiritual que representaron los años de la posguerra.

Así las cosas, es de vital importancia fijar la mirada en los textos que desde el enfoque del existencialismo publicó la Revista de Santander, ya que de este modo se pueden identificar las formas de divulgación que más utilizaron los escritores para dar a conocer esta perspectiva filosófica que logró hacerse presente en el ambiente cultural santandereano. Hay que mencionar que a lo largo de los dieciocho volúmenes se hallaron varios artículos que, de una u otra forma, se involucran con temáticas existencialistas, que si bien en su mayoría tienen un enfoque sartreano, no puede negarse la existencia de un amplio conocimiento, por parte de los autores, de obras fundacionales para el existencialismo, como las del filósofo danés Søren Kierkegaard o las del escritor ruso Fiódor Dostoievski.

De acuerdo con esto, se distinguen cinco líneas temáticas influidas por el existencialismo. La primera correspondió a la guerra, un tema bastante tratado entre los intelectuales de la época y en especial por Sartre, que nunca logró (y quizá nunca quiso) dejar atrás la guerra. "Con más intensidad que ningún otro intelectual de su tiempo, había confrontado, de modo sistemático, una serie de fenómenos del tiempo de guerra y del 
anterior a ella, en los meses y años que siguieron a la liberación de Francia y la derrota de Alemania" (Gumbrecht, 2015, p. 88).

En esta línea se distinguen cuatro artículos: "Responsabilidades", de Baldomero Sanín Cano (1945); "Comentario sobre la post-guerra”, de Augusto Espinosa (1945); "Nostalgia de la guerra”, por Jesús Zarate Moreno (1946), y "La humanización de la guerra" de Aníbal Arias Phillips (1946); estos escritos dedicaron sus líneas a un análisis sobre la situación que se vivió antes, durante y después de la Segunda Guerra Mundial, al observar los sucesos desde una perspectiva sumamente crítica que permitió denunciar la violación tanto de principios morales como filosóficos en las prácticas bélicas.

Por su lado, Baldomero Sanín Cano comentó los grados de responsabilidad de ser partícipe de la guerra. Para enfatizar su postura, usó como hilo conductor la situación ocurrida en una película inglesa que introduce al lector en el problema de la culpabilidad de Alemania, y asimismo de las personas que participaron de los crímenes cometidos durante la Segunda Guerra Mundial. Con esto señaló lo que Sartre (2009) ya había esbozado al exponer la idea de que "nuestra responsabilidad es mucho mayor de lo que podríamos suponer, porque compromete a toda la humanidad" (p. 34), pues todo hombre se convierte en responsable de sus actos en el momento en que elige llevarlos a cabo, o como ilustra Sanín Cano (1945) en las siguientes líneas,

Cuanto, al pueblo, al ejército, a los periodistas que ayudaron en esa obra, hay quienes apuntan que no son responsables, puesto que actuaron obedeciendo órdenes de sus jefes. No son materia pensante, sino materia explosiva. En tal caso la dinamita, la nitroglicerina, por su condición de explosivos, no son considerados como materia responsable, pero deben ser tenidos en observación, no sea que llegue un inconsciente y acerque el fuego o ejecute la percusión (p. 25).

Desde una mirada similar, Augusto Espinosa (1945) describe las causas que llevaron al estallido de la Segunda Guerra Mundial, los ámbitos que alteró y las posibilidades que vendrían después del fin del conflicto. $\mathrm{Al}$ igual que Sartre, puso énfasis en la responsabilidad individual: "El individuo por sí y ante sí resolvería sus problemas, ayudado por un equilibrio que se suponía implícito dentro del orden natural” (p. 54). En este sentido, el hombre resulta ser el único capaz de elegir entre culminar o seguir perpetrando "la terrible devastación y los infinitos sufrimientos” (p. 45) de una guerra que, sin 
embargo, no había mostrado su "verdadero rostro", como lo afirmaba Sartre en su artículo de 1945 titulado "El fin de la guerra", donde subrayó la dicotomía de las fuerzas que se enfrentaban en este conflicto y el estado latente de las consecuencias de esta para la humanidad (Gumbrecht, 2015, p. 35).

Por su parte, Jesús Zárate Moreno (1945) se interesa por retratar el ambiente que enmarcó aquellos años de guerra desde la visión de su cotidianidad en Colombia:

La guerra mundial creó entre nosotros ciertos hábitos intelectuales de los cuales resulta muy difícil prescindir en la paz. Durante cinco años nos acostumbramos en los diarios y en los radioperiódicos y en los cinematógrafos a la inevitable dosis de informaciones bélicas. No había proyecto de movilización o parte de batalla que no devoráramos desde el principio hasta el fin con avidez morbosa e insaciable. Ciudades bombardeadas, hogares destruidos, esperanzas fallidas, todo el horror de la guerra estaba en pocas horas al alcance visual o auditivo de nuestro conocimiento. Hubo un tiempo en que el resumen de las actividades épicas llegó a hacerse parte del pan que comíamos y del aire que respiráramos (p. 63).

Zárate concibe la vivencia de nuestro país ante este fenómeno histórico como algo superfluo, ya que no se experimentó en carne propia la sensación de aniquilación y desamparo propia de estos años, y los posteriores al conflicto, cuando era imposible huir de los estragos provocados; a propósito de esto, señala:

Es muy cómodo asistir a un episodio histórico tan trascendental como éste que hemos vivido sin tomar por nuestra cuenta ninguna de sus responsabilidades. La guerra sólo nos afectó por repercusión, superficialmente. La única noción que tuvimos de ella fue la de haber limitado ligeramente nuestros refinamientos indígenas, la de habernos privado de ciertos lujos superfluos (pp. 63-64).

Desde esta perspectiva, Zárate Moreno trata un tópico sumamente importante para el existencialismo, que se sintetiza con la frase "la existencia precede a la esencia” (Sartre, 2009, p. 27). Afirma que es muy difícil ocultar el fondo de barbarie que el hombre lleva en el alma (p. 64), no porque sea su esencia, sino porque este sentimiento se ha ido forjando a lo largo de sus relaciones con las guerras. El hombre ha hecho cotidiana la experiencia de la violencia, la ha acoplado a su mundo, por ello se siente tan escéptico de la dulzura de la paz, desconfía de su organización; y por esta razón surge la nostalgia de la guerra, una nostalgia que comprueba que los hombres "no pueden vivir sin devorarse unos con otros" (p. 66). 
Por otro lado, Aníbal Arias Phillips (1946) reflexionó en torno al debate de la humanización de la guerra, haciendo énfasis en la precariedad del pensamiento humano para mantener la paz y la calma sobre su voluntad conflictiva. Apuntó que "sólo el hombre, entre todos los animales de la creación, sin temor al ridículo macabro producido por su inteligencia sui géneris, proclama en su delirio inconsciente: yo humanizo la destrucción, ojalá total, de mis semejantes" (p. 96). Este punto de vista puede hallarse relacionado con la mala fe sartreana, ya que lo que Arias Phillips cataloga como una "estupidez grandiosa e incurable" que lleva al hombre a convertir a sus semejantes en animales para exterminarlos, no es más que un ocultamiento de la verdad que permite justificar crímenes, quitarles el rostro a los hombres y actuar con mala fe enmascarando una verdad desagradable que, sin embargo, es latente en cada conciencia (Sartre, 1950, p. 44).

La segunda línea temática tiene que ver con el compromiso. Acerca de esto, Sartre (2009) ya había comentado que comprometerse significa ser conscientemente libre en cada decisión; por ello es importante involucrarse totalmente con la humanidad, y no solo en casos particulares. Siguiendo esta alusión, se encontraron cinco artículos: "El hombre de la calle", escrito por Gustavo Wilches (1945); "La creación artística", de Hernando Téllez (1946); "Conciencia del escritor” (1946) y "El escritor y su tiempo", de Carlos Martín (1948), y "Los deberes de la inteligencia colombiana", de David Martínez Collazos (1957). En ellos, los autores intentaron, por un lado, explorar el papel que juega el hombre común en su sociedad, observando de cerca su individualismo; por el otro, indagar por el rol tanto del artista como del intelectual en la creación de un arte comprometido con su tiempo y su sociedad.

De esta manera, se pudo observar un marcado interés por exaltar la premisa sartreana de que escribir es ante todo comprometerse, mostrando la figura del escritor como un hombre común que es capaz de llevar su sensibilidad al punto de la creación, pues, como señala Hernando Téllez (1946), "Escribir es un acto de creación intelectual, que pide, por anticipado, un poco de imaginación, un poco de sensibilidad, un poco de emoción" (p. 11). Si el escritor no puede entregarse a este acto de empatía, no adquirirá la conciencia para plasmar una obra comprometida con su tiempo; entonces aparece como válida la pregunta de Carlos Martín (1946): 
[...] ¿por qué nos inclinamos hoy a buscar la palabra escrita que revela una fuerte efusión de conciencia? ¿Por qué preferimos la obra que ha sido creada con un sentido de misión casi religiosa? Quizás porque el mundo vive otras dimensiones. Y el hombre necesita un nuevo sentido de la vida y del mundo (p. 20).

En otras palabras, el lector busca repuestas a lo que el mundo le plantea, puntos de vista diferentes y opiniones que enriquezcan su perspectiva; por ello la crítica apunta a fijarse en aquel escritor que

[...] permanece en la superficie, al margen de los grandes problemas, deleitándose, egoísta y voluptuoso, en la palabra y no en la idea, en la forma y no en el contenido, sin enfrentarse con los conflictos del hombre y con los conflictos del infinito, sin que en el combate intervenga su existencia sino sus principios (Martín, 1948, p. 108).

Con esto, Martín pone sobre la mesa el caso particular de los escritores colombianos, señalando el reflejo de su preocupación por las coyunturas del momento en que se encontraron escribiendo y su postura ante la literatura comprometida con el hombre y su situación. Estas cuestiones fueron, sin duda, una piedra angular de la filosofía sartreana, concordando, finalmente, con el llamado que David Martínez Collazos (1957) le hizo al intelectual colombiano del siglo xx:

Todas las fuerzas vivas de la inteligencia colombiana coinciden en la urgencia impostergable de una unidad de pensamiento y de acción, que incorpore la empresa cultural y transcendente de nuestras actuales generaciones en el gran movimiento mundial, que anhela devolver al espíritu, todas las prerrogativas de su predominio y a la inteligencia creadora todos los medios de labrar el porvenir de la patria con un claro y perfecto sentido de grandeza, de bienestar y de mejoramiento. Sólo por este esfuerzo conjunto y perseverante de la inteligencia que guía y la inteligencia que obedece con los más elevados propósitos sociales y humanos, alcanzará Colombia el sitio de honor que le está reservado entre las naciones americanas (p. 50).

Una tercera línea temática correspondió a la inquietud metafísica acerca de Dios. Sobre esto se encontró un artículo titulado "La evolución homogénea de la idea de Dios", escrito por Clarence Finlayson (1957), filósofo chileno con marcado acento cristiano. En este texto se explora, desde la perspectiva religiosa, las posibilidades del hombre para encontrar en ideas trascendentales, que lo acompañen a lo largo de su existencia, un refugio para contrarrestar la vacuidad del ser. Este refugio, sin duda, 
es el Dios del cristianismo, quien conduce al hombre por el camino de la contemplación y de la acción, los cuales son el ideal de la vida cristiana y hacen parte de lo que se considera una existencia plena.

En la cuarta línea temática aparecen cuentos y poesías, que en su orden de publicación fueron: "El grande actor", escrito por Octavio Amórtegui (1947); "El abismo", de Luis López Rodríguez (1948); "El perfecto lector", de Hernán Gómez Ortiz (1950), “Tres poemas”, de Carmen Ortiz de Gómez (1964), y "Sísifo”, de Ernesto Camargo Martínez (1967). Estos textos, desde perspectivas diferentes, dejaron ver claramente el tema de la condición humana, pues a partir de situaciones cotidianas en las que el humor, la sátira, el absurdo y la nostalgia se entremezclan para mostrar las realidades del mundo, los autores introdujeron una crítica tajante o una reflexión importante en la voz de algún personaje.

Poesías como las de Carmen Ortiz de Gómez Mejía y las de Ernesto Camargo Martínez permitieron evidenciar el aire existencialista que corría entre los escritores locales. Por su parte, Ortiz dejó ver su deseo por trasmitirle al lector una sensación que va más allá de un amor perdido o un sueño roto, para introducirse en senderos más profundos de la sensibilidad humana, lugar donde adquieren sentido versos como "Yo estoy vacía de días y de palabras / Qué haremos mañana? / Qué haremos siempre?” (Ortiz, 1964, p. 69). Camargo Martínez, por otro lado, exaltó la figura de Sísifo en clara alusión al famoso texto de Albert Camus (1913-1960) titulado El mito de Sísifo (1942). Si bien este filósofo nunca se consideró existencialista, sí influyó y se vio influido por esta corriente.

Por último, la quinta línea temática es precisamente la del existencialismo como filosofía. En la revista se encontraron artículos que de manera específica realizaron un recorrido detallado por esta corriente filosófica, empezando por el texto titulado "Filosofía de la existencia", de Józef Maria Bocheński (1950), donde se expone la temática existencialista, desde sus representantes, sus orígenes, sus rasgos característicos y sus alcances, abriendo un espacio para que el lector pudiese enterarse, de primera mano, sobre los postulados que posteriormente pasarían a ser discutidos en el ensayo "Dos posiciones antagónicas del hombre ante el mundo", de Henry Serrano Uribe (1950), en el que el autor intentó mostrar que el existencialismo llega a ser una posición demasiado radical para el hombre actual, pues la disposición de esta filosofía podría arrojarlo a la desesperación, y lo prudente, para ese momento, sería no dejar de lado la 
esperanza. Serrano utiliza las premisas del existencialismo para evidenciar su conocimiento de este, y a la vez su rechazo a esta visión.

Otros artículos de esta misma línea son: "Dostoievski el hombre que llegó a la religión por el sufrimiento", de Ricardo Serpa Cuesto (1958) y "El teatro del absurdo", de Andrés Holguín (1958), que se encargaron de estudiar tendencias específicas dentro del existencialismo, haciendo énfasis en la obra de autores como Fiódor Dostoievski. Serpa Cuesto presentó al escritor ruso como un mártir que por medio de un camino de sufrimiento llegó a la creación, hallando su inspiración en el "amor al prójimo, especialmente al prójimo desvalido y preferentísimamente al prójimo vejado, vilipendiado. Lo más puro de su corazón fue siempre para las víctimas de las malas leyes" (Serpa Cuesto, 1958, p.189). Por otro lado, Holguín exaltó el papel del teatro del absurdo como una expresión social con tendencia filosófica que retrató a la perfección las peripecias del mundo contemporáneo.

\section{Conclusiones}

En medio de un contexto cambiante y conflictivo, la Revista de Santander fue un punto aparte inmerso en las disputas de un país que pasaba de un conflicto para entrar en otro. Las cuestiones políticas y partidistas no se tocaron. Solo Gustavo Serrano Gómez en 1945 realizó un perfil grandilocuente del presidente Alberto Lleras, mostrándolo como "una figura patriótica" y "el tránsito de una generación hacia el campo de la actividad rectora" (Serrano, 1945, pp. 143-145). Escritores, periodistas y políticos lograron sacar adelante una revista cultural que recogía la mejor producción del departamento de Santander en todos los ámbitos, y además acercaba al lector a nuevas lecturas, nuevas discusiones y nuevos contextos.

Con esto, se pudo ver cómo el ambiente convulso que atravesó el país y el mundo, especialmente después de 1945, entre anhelos de paz, nuevas guerras y conflictos inacabados, impresionó a este grupo de políticos, escritores, poetas y periodistas. No se hablaba de partidismos o de política, pero era inevitable pensar en ello. Las conciencias eran palpables. Desde ese momento el mundo no volvió a ser el mismo, como apunta Gumbrecht (2015): "Parecía que aquellos que habían sobrevivido a la guerra estaban tan ocupados luchando por sobrevivir en la nueva realidad cotidiana de paz que no podían apreciar sus propios logros, aún menos, al parecer, podían medir su propia ceguera" (pp. 13-14). 
Así, el mundo se encontró sumido en una profunda sensación de crisis que propició el surgimiento de puntos de vista sumamente diferentes y en ocasiones antagónicos, reflejados en las posturas intelectuales de autores como los que escribieron en la Revista de Santander; aunada a este fenómeno mundial, la situación política colombiana de aquella época, enfrascada en un periodo de gran violencia, contribuyó a la sensación generalizada de una falta de sentido y dirección que a la larga permitió el acercamiento de los distintos estudiosos de las letras a corrientes como el existencialismo. Por otro lado, aunque para Colombia la Segunda Guerra Mundial no significó una participación bélica muy activa, sí simbolizó un intercambio cultural bastante amplio, cuestión que permitió la llegada de nuevas perspectivas que a la larga terminarían formando parte del sentir colectivo.

\section{Referencias bibliográficas}

Acevedo Tarazona, Á. (2017). 1968. Historia de un acontecimiento: utopía y revolución en la universidad colombiana. Bucaramanga: Universidad Industrial de Santander.

Amórtegui, O. (1947). El grande actor. Revista de Santander 3, pp. 93-95.

Arias Phillips, A. (1946). La humanización de la guerra. Revista de Santander 6, pp. 91-96. Beltrán Pinzón, A. (2006). Presentación. Revista de Santander 1, pp. 7-9.

Bobbio, N. (1949). El existencialismo: ensayo de interpretación. México: Fondo de Cultura Económica.

Bocheński, J. M. (1950). Filosofía de la existencia. Revista de Santander 10, pp. 15-20.

Camus, A. (2017). El mito de Sísifo. Madrid: Alianza.

Camargo Martínez, E. (1967). Sísifo. Revista de Santander 18, pp. 73-74.

Espinosa, A. (1945). Comentarios sobre la postguerra. Revista de Santander 3, pp. 45-59.

Finlayson. C. (1957). La evolución homogénea de la idea de Dios. Revista de Santander 11, pp. $85-94$.

Gómez Ortiz, H. (1950). El perfecto lector. Revista de Santander 6, pp. 103-107

Gumbrecht, H. U. (2015). Después de 1945. La latencia como origen del presente. México: Universidad Iberoamericana.

Henderson, J. (2006). La modernización en Colombia: los años de Laureano Gómez 18891965. Medellín: Editorial Universidad de Antioquia.

Holguín, A. (1958). El teatro del absurdo. Revista de Santander 15, pp. 37-51.

Jaramillo Vélez, R. (1998). Colombia: La modernidad postergada. Bogotá: Selene Editores. López Rodríguez, L. (1948). El abismo. Revista de Santander 4, pp. 99-105.

Martín, C. (1946). Conciencia del escritor. Revista de Santander 5, pp. 17-21.

Martín, C. (1948). El escritor y su tiempo. Revista de Santander 8, pp. 107-111.

Martínez Collazos, D. (1957). Los deberes de la inteligencia colombiana. Revista de Santander 11, pp. 47-50.

Ortiz de Gómez, C. (1964). Tres poemas. Revista de Santander 17, pp. 69-71. 
Sanín Cano, B. (1945). Responsabilidades. Revista de Santander 3, pp. 17-25.

Sartre, J. P. (1950). ¿Qué es la literatura? Buenos Aires: Losada.

Sartre, J. P. (2009). El existencialismo es un humanismo. Barcelona: Edhasa.

Serpa Cuesto, R. (1958). Dostoievski el hombre que llegó a la religión por el sufrimiento. Revista de Santander 8, pp. 189-192.

Serrano Blanco, M. (1989). La vida es así. Bucaramanga: Imprenta del Departamento.

Serrano Gómez, G. (1945). Alberto Lleras Camargo. Revista de Santander 3, pp. 143-145.

Serrano Uribe, H. (1950). Dos posiciones antagónicas del hombre ante el mundo. Revista de Santander 10, pp. 21-29.

Téllez, H. (1946). La creación artística. Revista de Santander 5, pp. 11-16.

Wilches, G. (1945). El hombre de la calle. Revista de Santander 3, pp. 61-65.

Zárate Moreno, J. (1945). Nostalgia de la guerra. Revista de Santander 4, pp. 63-66. 